\title{
Quantifying the contribution of sea lice from aquaculture to declining annual returns in a wild Atlantic salmon population
}

\author{
Samuel Shephard*, Patrick Gargan \\ Inland Fisheries Ireland, 3044 Lake Drive, CityWest Business Campus, Dublin 24, D24 Y265, Ireland
}

\begin{abstract}
Atlantic salmon Salmo salar has shown declines in abundance associated with reduced survival during marine life stages. Key impacts on survival may include a changing ocean environment and salmon louse Lepeophtheirus salmonis infestation from aquaculture. A $26 \mathrm{yr}$ record from the Erriff River (Western Ireland) was used to evaluate the contribution of sea lice from salmon aquaculture to declining returns of wild 1 sea-winter (1SW) salmon. Statistical models suggested that returns were $>50 \%$ lower in years following high lice levels on nearby salmon farms during the smolt out-migration. The long-term impact of salmon lice was explored by applying predicted annual loss rates as a multiplier to observed 1SW salmon returns. This produced a 'lice-corrected' return time series, i.e. an estimate of how returns might have looked in the absence of a serious aquaculture lice impact. The corrected time series was adjusted to account for some reduction in recruitment due to lost spawners. Comparing observed and lice-corrected time series suggested that salmon lice have strongly reduced annual returns of 1SW Erriff salmon, but that the salmon lice impact does not explain a declining trend in this population.
\end{abstract}

KEY WORDS: Lepeophtheirus salmonis $\cdot$ Salmo salar $\cdot$ Salmon smolts $\cdot$ Salmon farming $\cdot$ Ricker stock recruitment

\section{INTRODUCTION}

Atlantic salmon Salmo salar is an iconic anadromous fish species that has shown marked declines in abundance in recent decades (Limburg \& Waldman 2009). Decreased survival rate in the marine environment, rather than in natal rivers, seems to explain the current poor state of many salmon populations (ICES 2016). Marine survival can be partitioned into coastal (transitional and inshore waters) and oceanic (offshore and open ocean) components. The coastal component operates during the first migration of juvenile salmon (smolts) out of their natal river. Events during such early life stages can have an impact on subsequent marine survival of salmon (Holsman et al. 2012). The oceanic component refers to fish in summer nursery areas offshore and in winter feeding areas. In addition to natural mortality, each compo-

*Corresponding author: sam.shephard@fisheriesireland.ie nent of marine survival is influenced by anthropogenic pressures.

Coastal pressures frequently interact (Parrish et al. 1998) and include local pollution (Larsson et al. 1996, McCormick et al. 1998, Johnson et al. 2007) and increased rates of sea lice Lepeophtheirus salmonis infestation associated with salmon aquaculture (e.g. Krkošek et al. 2007, Costello 2009). Sea cage aquaculture causes sea lice on sympatric wild fish to increase (Frazer 2009). Marine survival of wild pink salmon has been related negatively to lice density on farmed salmon (Marty et al. 2010, Krkošek et al. 2011) and to observed lice infestation on out-migrating juvenile wild fish (Peacock et al. 2013). The negative impact of sea lice on salmonid survival appears to be exacerbated by warmer environmental conditions (Bateman et al. 2016, Shephard et al. 2016). In the ocean, salmon respond to large-scale climate

(C) The authors 2017. Open Access under Creative Commons by Attribution Licence. Use, distribution and reproduction are unrestricted. Authors and original publication must be credited. 
forcing (ICES 2016) by the North Atlantic Oscillation (NAO) and the Atlantic Multi-decadal Oscillation (AMO) that drive sea surface temperature (SST) and thus salmon thermal habitat (Friedland et al. 1993, 2003, Jonsson \& Jonsson 2004, Mills et al. 2013) and associated prey dynamics (Beaugrand \& Reid 2012, Defriez et al. 2016). Recent studies suggest that ocean warming has had a negative impact on oceanic growth and survival (McCarthy et al. 2008, Todd et al. 2008, Friedland et al. 2009) and genetic diversity (Horreo et al. 2011) of Atlantic salmon.

Strong environmental impacts on marine life stages of salmon have

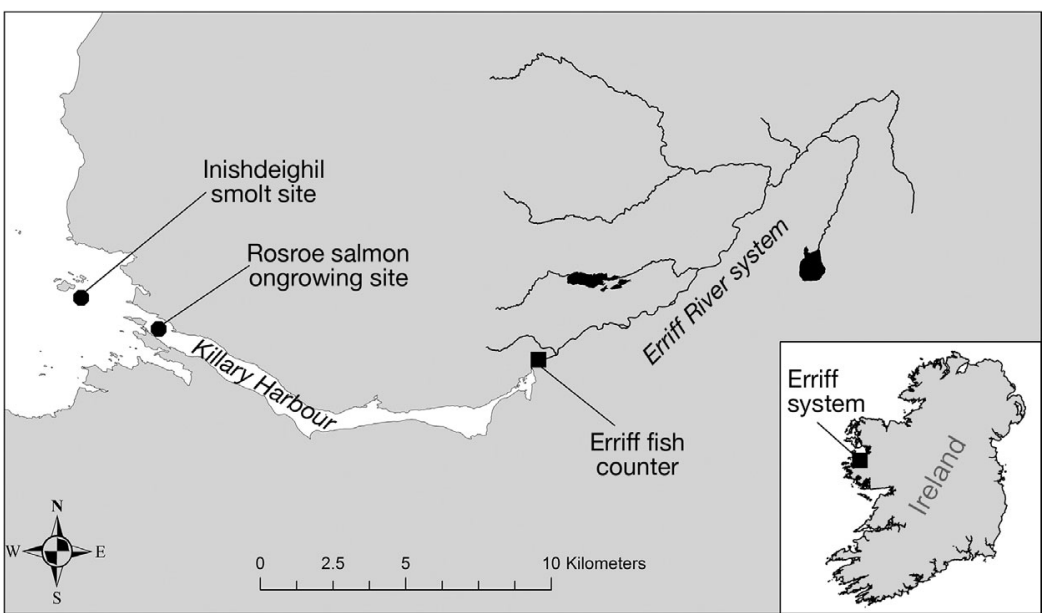

Fig. 1. Erriff River system and Killary Harbour, Ireland, showing the location of the salmon aquaculture sites and the fish counter

sible effects of sea lice from aquaculture on marine survival of a wild Atlantic salmon population. We used a 26 yr record from the Erriff to investigate relationships between sea lice (salmon lice Lepeophtheirus salmonis; hereafter simply sea lice) infestation on the Killary salmon farm and annual returns of wild 1 sea-winter (1SW) Erriff salmon, while accounting for unexplained inter-annual variability in marine survival of this population.

\section{MATERIALS AND METHODS \\ MATERIALS AND METHODS} survival (Vollset et al. 2016). The contribution of sea lice to overall marine survival of wild Atlantic salmon remains an important knowledge gap, particularly in the context of changing oceanographic conditions and the long-term decline of many populations. Parsing out coastal sea lice effects might contribute to understanding of changing high-seas marine survival, and possibly guide management of lice on salmon farms to reduce impacts on wild populations (Peacock et al. 2013).

The Erriff River system in the west of Ireland is designated as a Special Area of Conservation for Atlantic salmon under the European Union Habitats Directive (92/43/EEC). This system has supported salmon angling since the late $19^{\text {th }}$ century, with annual returns of fish to the river being recorded for several decades. Salmon aquaculture commenced in the Erriff estuary (Killary Harbour) in the mid-1980s, and licensed annual production increased from $450 \mathrm{t}$ in 1986 to 2200 t by 2006. Levels of sea lice infestation on the Killary salmon farm have been recorded since 1991. The position of this salmon farm at the entrance to a narrow fjord (Fig. 1) makes the Erriff system an excellent 'natural experiment' on the pos-

\section{Study system}

The Erriff River has a catchment area of $166 \mathrm{~km}^{2}$ and discharges into Killary Harbour, a $15 \mathrm{~km}$ long fjord in the west of Ireland (Fig. 1). Data series used in the current study comprised:

(1) Annual wild Atlantic salmon Salmo salar returns: (a) count of 1SW Erriff fish returning to the river, and (b) estimated return (accounting for annual commercial fishing mortality at sea, $F$; see below) of Erriff salmon to the Irish coast (1987-2016).

(2) Annual aquaculture lice count estimate: average number of mobile (pre-adult and adult) sea lice (Lepeophtheirus salmonis) fish ${ }^{-1}$ on the Killary salmon farm (Fig. 2) in April (www.marine.ie/Home/sitearea/areas-activity/aquaculture/sea-lice), multiplied by an estimate of the total number of fish on the farm (taken as 0 in 1986 prior to farming and recorded for 1991-2016. For years when the smolt on-growing site (Fig. 1) was active, estimated total lice from this site were added to the total for the salmon farm. The current analysis related the number of returning 1SW 


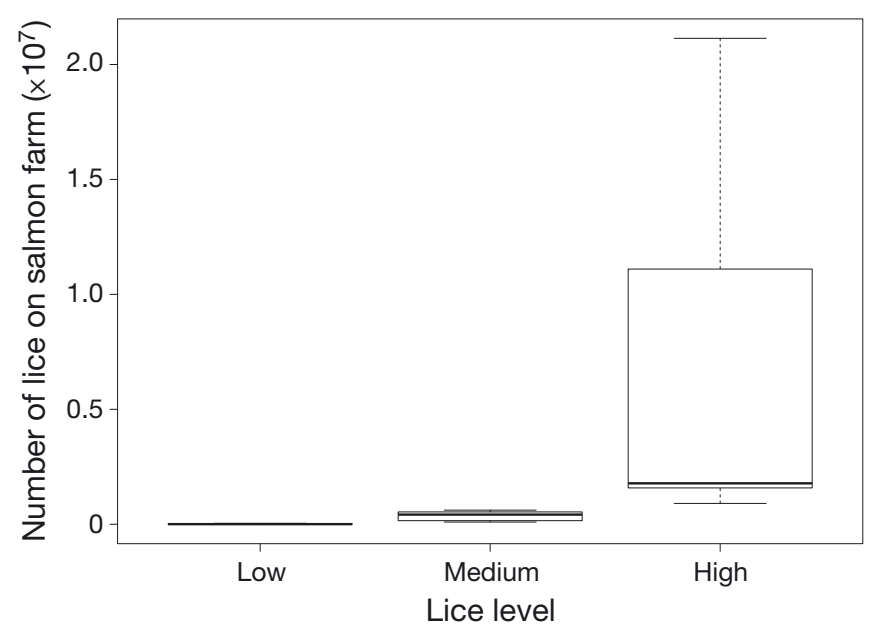

Fig. 2. Numbers of sea lice in each level of the categorical lice variable $L$ cat $2_{i}$. Summary statistics are the median of the data, the lower and upper quartiles (25\% and $75 \%)$ and the minimum and maximum values. There are 8 data points (years) for the Low lice level, and 9 data points in each of Medium and High lice levels

salmon to the number of sea lice on aquaculture sites in the previous year, i.e. when those 1SW fish outmigrated as smolts. Aquaculture lice counts for April were used as an index of lice infestation pressure on wild migrating salmon smolts because records from 2002-2016 ( $N=15684$ smolts, Inland Fisheries Ireland unpublished data) indicated that $88 \%$ of the wild salmon smolt run in the Erriff catchment occurs between 1 April and 10 May.

\section{Estimation of annual wild salmon returns}

Two salmon return series were used. Salmon entering the Erriff are recorded by a fish counter approximately $200 \mathrm{~m}$ upstream of the river mouth. The annual count of $1 \mathrm{SW}$ salmon $S$ returning to the Erriff River in year $i\left(S_{\text {iRiver }}\right)$ was calculated as the sum of 1SW salmon rod caught (killed) below the fish counter and the number recorded by the counter. $S_{\text {iRiver }}$ represents exact known counts of fish entering the river, but does not account for variable levels of $F$ prior to return. Estimated return to the Irish coast $\left(S_{\text {iCoast }}\right)$ was estimated by using $F$ time series to expand $S_{\text {iRiver. }}$ Commercial drift and draft net fisheries for wild salmon both operated off the Irish coast during the early study period, viz. 1987-2006, but fishing was restricted to inshore draft netting from 20072016. $F$ was calculated slightly differently for these 2 time periods:

(1) Combined (drift and draft net) mean annual exploitation rate $F$ for $1 \mathrm{SW}$ salmon has been calcu- lated for 2 west of Ireland salmon stocks: Corrib and Burrishoole (Ó Maoiléidigh et al. 2015). These averaged $F$ estimates (Fig. 3) were used to raise $S_{\text {iRiver }}$ to an estimate of $S_{\text {iCoast }}$ for 1987-2006, where $S_{\text {iCoast }}=$ $S_{\text {iRiver }} /(1-F)$. These estimated $S_{\text {iCoast }}$ values suggest that Erriff fish contributed about $1.3 \%$ to the total annual catch of salmon in the Irish drift net fishery. This value is somewhat uncertain, as $F$ was derived from a subsample of the overall commercial catch (Ó Maoiléidigh et al. 2015). However, it is similar to independent estimates of the contribution of Erriff salmon to the drift net catch based on assigning captured fish to their natal river using a genetic signature. Genetic assignment suggested that the total drift net catch comprised 1.7\% Erriff fish in 2005 and $2.5 \%$ Erriff fish in 2006 (Anon 2008).

(2) Total annual catch in the Killary draft net fishery $S_{\text {id }}$ is recorded and can be allocated to 3 local rivers including the Erriff. These 3 rivers have salmon conservation limits (CLs) of 1383 (Erriff), 136 (Culfin) and 165 (Delphi), where CL is defined as the spawning stock level that produces long term average maximum sustainable yield as derived from the adult to adult stock and recruitment relationship, and is quantitatively derived for each river by the Irish Standing Scientific Committee for Salmon. The Erriff CL represents $82 \%$ of the summed CL for the 3 rivers in Killary; $F$ for 2007-2016 was thus calculated as $0.82 \times S_{i d} /\left(0.82 \times S_{i d}\right)+S_{\text {iRiver }}$ and $S_{\text {iCoast }}=S_{\text {iRiver }} /$ $(1-F)$ as above.

\section{Statistical analysis: estimating the lice effect on salmon returns}

By observation $i$, the data consisted of $\left(S_{i}, Y, L_{i}\right)$, where $S_{i}$ is the number of Erriff salmon returning (to either the river or the coast) in sampling year $Y_{i 1}, \ldots, 30$ (1987-2016) and $L_{i}$ is the estimated total number of sea lice on the Killary salmon farm (on-growing and smolt sites) in the previous year $Y_{i-1}$ (no data for 1987-1990). Sea lice number was also interpreted as a categorical variable with 3 intensity levels (Low, Medium, High) in order to facilitate interpretation of lice impacts across (continuous) $Y_{i}$. Two approaches to categorizing $L_{i}$ were tested: (1) ccat $_{i}$ according to $0-25^{\text {th }}, 25^{\text {th }}-75^{\text {th }}$ and $75^{\text {th }}-100^{\text {th }}$ percentiles of $L_{i}$ and (2) $L$ cat $2_{i}$ using natural divisions in $L_{i}$, which had groups of data points at 3 distinct levels (Fig. 2).

We developed statistical models to quantify possible effects of sea lice on each of $S_{\text {iRiver }}$ and $S_{\text {iCoast }}$ (1987 and 1992-2016), while accounting for an observed declining trend in salmon returns, and also for other 

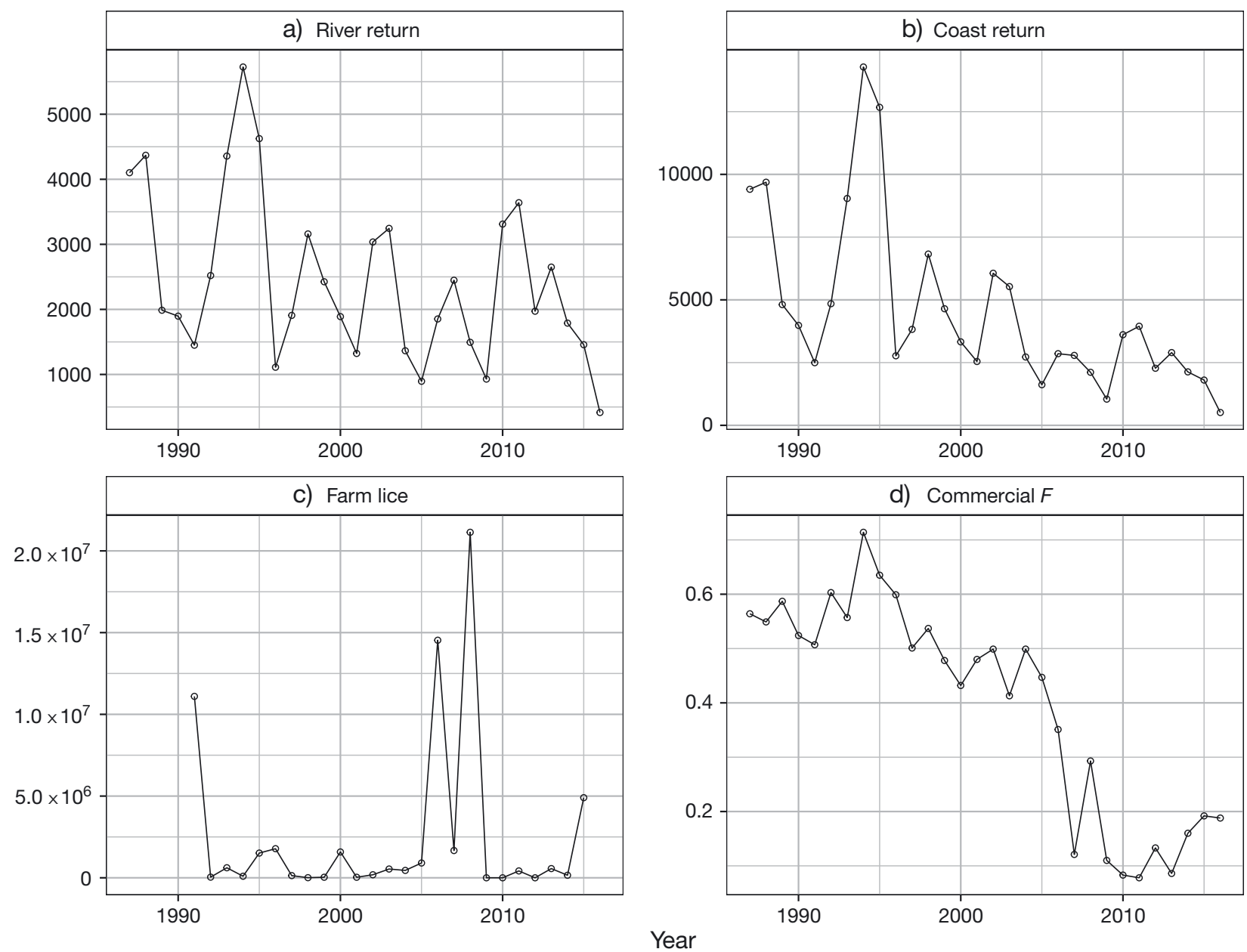

Fig. 3. Time series of returns of 1 sea-winter (1SW) Erriff River Atlantic salmon (a) to the river ( $S_{\text {iRiver }}$ ) and (b) to the Irish coast $\left(S_{\text {iCoast }}\right) ;($ c) estimated number of sea lice in the Killary salmon farm; and $(d)$ estimated commercial fishing mortality $(F)$ for Erriff salmon

unexplained annually varying environmental drivers of marine mortality. The negative trend in Erriff salmon returns was incorporated by using standardised (subtracting the mean and dividing by the standard deviation) $Y_{i}$ as a continuous fixed variable. Unexplained annual effects on salmon returns were incorporated by specifying year as a categorical variable $Y_{C a}{ }_{i}$, and including this variable as a random effect $\alpha_{i}$ on the intercept. Ycat ${ }_{i}$ thus captures inter-annual effects on returns that cannot be accounted for by the lice and $Y_{i}$ covariates (see Elston et al. 2001) and which are expected to largely comprise environmental variability. As an observation level random effect (OLRE), Ycat ${ }_{i}$ also acts as a simple and robust means to account for overdispersion in count data (Harrison 2014). The 5 variables specified above $\left(S_{i}, Y_{i}, L_{i}, L c a t_{i}, L c a t 2_{i}\right)$ were used to specify a comprehensive set of 7 candidate models, all including Ycat $_{i}$ as a random effect $\alpha_{i}$ (Table 1).
The same modelling process was applied to each of $S_{\text {iRiver }}$ and $S_{\text {iCoast }}$ separately. In each case, the model set (Table 1) was fit using a Poisson GLMM (lme4 package in R, Bates et al. 2015). The full model had the form:

Table 1. Set of 7 candidate models of the number of 1 seawinter (1SW) Erriff River Atlantic salmon returning to the river and to the Irish coast (1987 and 1992-2016). Model parameters are defined in 'Materials and methods'

\begin{tabular}{|ll|}
\hline No. & Model \\
\hline 1 & $\log \left(\mu_{i}\right)=Y_{i}+\alpha_{i}$ \\
2 & $\log \left(\mu_{i}\right)=\ln \left(L_{i}\right)+\alpha_{i}$ \\
3 & $\log \left(\mu_{i}\right)=\ln \left(L_{i}\right)+Y_{i}+\alpha_{i}$ \\
4 & $\log \left(\mu_{i}\right)=\operatorname{Lcat} 1_{i}+\alpha_{i}$ \\
5 & $\log \left(\mu_{i}\right)=\operatorname{LCat} 1_{i}+Y_{i}+\alpha_{i}$ \\
6 & $\log \left(\mu_{i}\right)=\operatorname{Lcat} 2_{i}+\alpha_{i}$ \\
7 & $\log \left(\mu_{i}\right)=\operatorname{Lcat} 2_{i}+Y_{i}+\alpha_{i}$ \\
\hline
\end{tabular}




$$
\begin{aligned}
& S_{i} \sim \operatorname{Poisson}\left(\mu_{i}\right) \\
& E\left(S_{i}\right)=\operatorname{var}\left(S_{i}\right)=\mu_{i} \\
& \log \left(\mu_{i}\right)=L_{i}+Y_{i}+\alpha_{i} \\
& \alpha_{i} \sim N\left(0, \sigma_{\text {Ycat }}^{2}\right)
\end{aligned}
$$

Akaike's Information Criterion (AIC) was used to compare model fits, where any models within 2 AIC units of the best-fitting model would be considered to have similar fit to the data. Various diagnostics were used to explore model fit and statistical assumptions: (1) plots of standardised (Pearson) residuals were checked for homogeneity, (2) linearity in the relationships between salmon return and tested (continuous) covariates was evaluated by plotting Pearson residuals against each covariate in the model and fitting a GAM to visualize any non-linear patterns, and (3) temporal autocorrelation in model residuals was evaluated using the acf function in R.

Selected (lowest AIC) final models for both $S_{\text {iRiver }}$ and $S_{\text {iCoast }}$ included sea lice characterised as $L$ cat $2_{i}$. The effect on return of 1SW Erriff salmon of sea lice level (Lcat2 ${ }_{i}$ : Low, Medium, High) in each of these selected models was visualized using the R package 'Effects', where other variables were held at average values (Fox 2003). The random effect of year Ycat $_{i}$ was plotted with $95 \%$ confidence intervals. Salmon returns at each lice level were also predicted (predict function in R) and plotted for each level of $Y_{c a t}$ (26 levels, i.e. years), considering 3 periods of the time series $Y_{i}$ (Early, Mid, Recent) to show how the predicted (within year) lice effect on salmon returns compared to the (across year) random year effect (assumed to express annually-varying environmental effects on returns).

\section{Predicting long-term salmon returns without sea lice}

The models above predicted that the average return of 1SW Erriff salmon to the river is reduced by $18.6 \%$ following a year of Medium lice levels and $52.2 \%$ following a year of High lice levels; returns to the coast were predicted to be reduced by 2.3 and $49.6 \%$, respectively. We used these lice impact levels and a fitted stock-recruitment relationship to estimate how annual salmon returns might have looked over the last $25 \mathrm{yr}$ in the absence of a serious impact of sea lice from aquaculture:

(1) Observed annual salmon returns (each of $S_{\text {iRiver }}$ and $S_{\text {iCoast }}$ ) were first 'lice-corrected' (multiplied up) according to the annual loss rates predicted from modelling; loss rates were expressed as the percentage difference between predicted salmon returns at each of Medium and High lice levels and the predicted return at Low lice levels in an average year. For example, the observed return to the river in 1992 was 2520 salmon, but because the lice level was 'High' during the smolt run in 1991, it is predicted that this run represents a $52.2 \%$ reduction compared to the run that would have happened in Low lice conditions (given average environmental conditions as expressed by $Y_{c a t}$ ). The lice-corrected return $S_{i}$ was thus calculated as $S_{1992}=2520 /(100-52.2) \times$ $100=5272$ salmon.

(2) To realistically estimate the cumulative impact of sea lice on long-term returns of Erriff salmon, it was then necessary to account for likely diminished recruitment associated with loss of potential spawners (hereafter 'missing spawners') that never returned to the river/coast because they suffered lice-related mortality as smolts. $85 \%$ of Erriff salmon migrate as $2 \mathrm{yr}$ smolts, resulting in a 4 yr generation time (White et al. 2016). Adult-to-adult Ricker stock recruitment $(S R)$ relationships were produced for each of river and coast returns (see Fig. 6), where $S$ is the observed return $S_{i}$ and $R$ is the lice-corrected return $4 \mathrm{yr}$ later, $S e_{i+4}$. These $S R$ curves were used to estimate peak (asymptotic) recruitment $R p$, and the peak stock $S p$ at $R p$, for each of $S_{i R i v e r}$ and $S_{\text {iCoast. }}$ The number of 'missing spawners' $S m_{i}$ in each year was then estimated as $S m_{i}=S e_{i}-S_{i}$, with $S e_{i}$ being capped at $S p$ on the assumption that once $S p$ is exceeded, there is no further positive effect on subsequent recruitment.

(3) A lice-corrected adult-to-adult return rate, $R R$, was then estimated for each year $Y_{i}$ in each of $S_{\text {iRiver }}$ and $S_{i \text { Coast }}$ assuming that each $S_{i}$ comprised $85 \% 4 \mathrm{yr}$ and $15 \% 5 \mathrm{yr}$ fish (White et al. 2016), such that $R R_{i}$ is the weighted mean of $\left(\mathrm{Se}_{i} / \mathrm{S}_{\mathrm{i-4}}\right)$ and $\left(\mathrm{Se}_{i} / \mathrm{S}_{\mathrm{i-5}}\right)$ with weightings being 85 and 15, respectively. These $R R_{i}$ are an estimate of the number of returning fish expected (given Low lice levels) from each parent fish. $85 \%$ of missing fish $\mathrm{Sm}_{i}$ were then allowed to contribute recruits $S r_{i}$ to the return 4 yr later according to the estimated return rate $R R_{i}$, where this contribution $S r_{i+4}=\left(0.85 \times S m_{i}\right) \times R R_{i+4}$. The remaining $15 \%$ of missing fish contributed to recruitment 5 yr later as $S r_{i+5}=\left(0.15 \times S m_{i}\right) \times R R_{i+5}$. To restrict un-quantified uncertainty in this process, missing fish were only considered to contribute recruits to a single generation.

(4) Finally, a total expanded return Stot ${ }_{i}$ including the annual lice-correction and the associated (1 generation) effect on recruitment, was calculated as $S_{t o t}$ $=S e_{i}+S r_{i}$. Time series of $S_{i}$ and $S t o t_{i}$ were plotted together for visual comparison, with the first $4 \mathrm{yr}$ of $S t o t_{i}$ obviously not including any $S r_{i}$ as there were no lice data for their respective parent generations. 


\section{RESULTS}

\section{Estimating the lice effect}

Model 7 (see Table 1) was the best fitting model for both $S_{\text {iRiver }}(\triangle \mathrm{AIC}=3.8)$ and $S_{\text {iCoast }}(\Delta \mathrm{AIC}=4.0)$. The model including only year as a continuous variable (Model 1, Table 1), had $\triangle \mathrm{AIC}>8.0$ compared to Model 7 fitted to $S_{\text {iRiver, }}$ and $\Delta \mathrm{AIC}>11.0$ compared to Model 7 fitted to $S_{\text {iCoast, }}$ indicating that Lcat $2_{i}$ strongly improved model fit. Diagnostic plots did not show important heterogeneity or non-linearity in residuals, and there was no significant temporal autocorrelation. There were significant negative effects of the continuous year variable $Y_{i}$ on each of $S_{\text {iRiver }}$ and $S_{\text {iCoast }}$ i.e. long-term declines in 1SW salmon returns (Table 2). There were also significant negative effects of High sea lice levels $L c a t 2_{i}$ during the smolt outmigration on each of $S_{\text {iRiver }}$ and $S_{\text {iCoast }}$ in the following year (Table 2). Predicted returns were reduced at Medium and strongly reduced at High lice levels. For an average random year $Y_{\text {cat }}$ and continuous year $Y_{i}$ : the predicted $S_{\text {iRiver }}$ (1394 fish) at High lice levels was $52.2 \%$ less than the predicted return (2919 fish) at Low lice levels (Fig. 4a); predicted $S_{\text {iCoast }}$ (2226 fish) at High lice levels was $49.6 \%$ less than the predicted return (4419 fish) at Low lice levels (Fig. 4b).

The OLRE Ycat $_{i}$ captures any important patterns in the response variable that cannot be modelled by other terms in the model (Zuur et al. 2015). Strong variation in salmon returns across levels of $Y_{\text {cat }}$ indicated considerable inter-annual variation in salmon returns to the river and coast (Fig. 5), probably reflecting environmental effects. However, the predicted $52.2 \%$ reduction in $S_{\text {iRiver }}$ following 'High' lice levels is greater than the average year-to-year (Ycat to $Y_{\text {cat }}{ }_{i+1}$ ) change in predicted returns (mean =

Table 2. Results from selected models (Model 7, see Table 1) of annual returns of 1 sea-winter (1SW) Erriff River Atlantic salmon returning to the river $\left(S_{\text {iRiver }}\right)$ and to the Irish coast

$$
\left(S_{\text {iCoast }}\right)
$$

\begin{tabular}{|lrcrr|}
\hline River returns & Estimate & SE & Z-value & $\mathrm{p}$ \\
\hline (Intercept) & 7.979 & 0.143 & 55.917 & $<0.001$ \\
Year & -0.277 & 0.081 & -3.412 & $<0.001$ \\
Lice level Medium & -0.206 & 0.197 & -1.045 & 0.296 \\
Lice level High & -0.739 & 0.196 & -3.772 & $<0.001$ \\
Coast returns & & & & \\
(Intercept) & 8.394 & 0.129 & 65.064 & $<0.001$ \\
Year & -0.551 & 0.073 & -7.512 & $<0.001$ \\
Lice level Medium & -0.023 & 0.178 & -0.128 & 0.898 \\
Lice level High & -0.686 & 0.177 & -3.871 & $<0.001$ \\
\hline
\end{tabular}

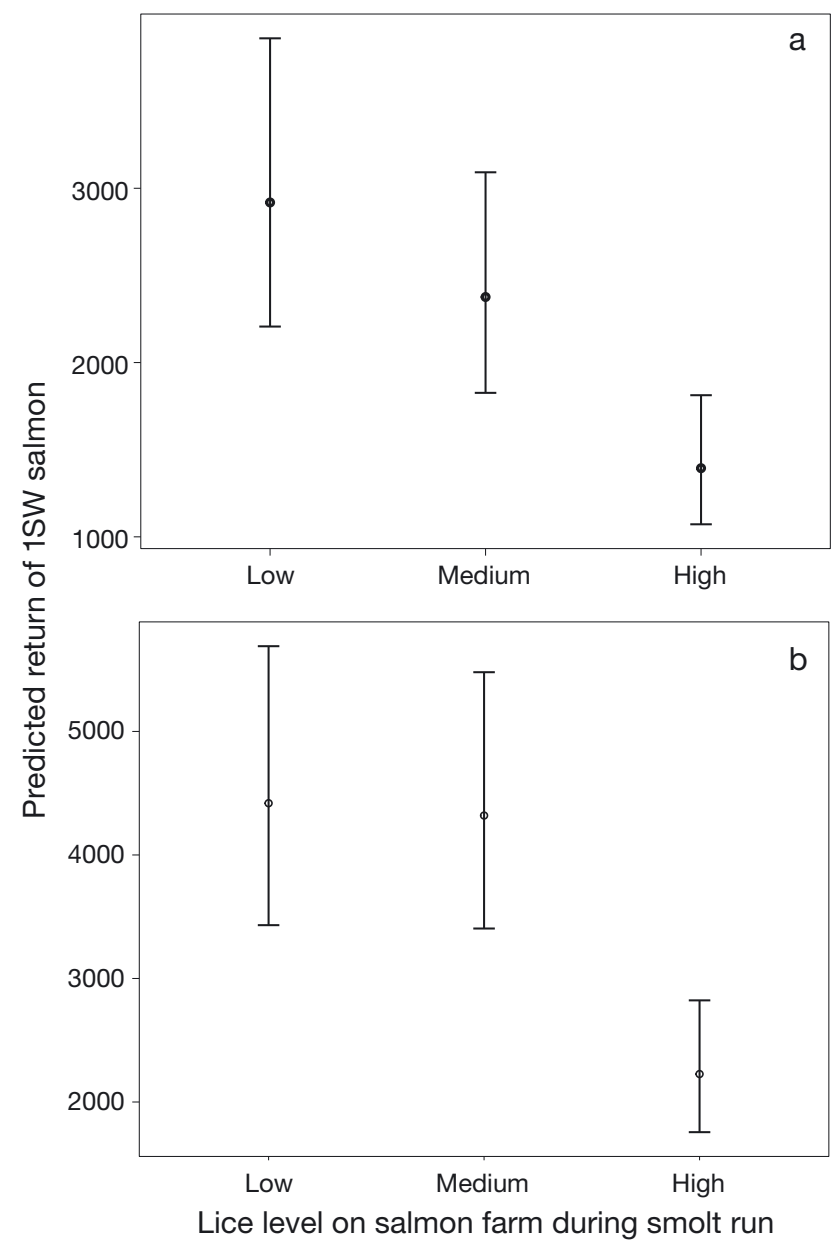

Fig. 4. Predicted return of 1 sea-winter (1SW) Erriff River Atlantic salmon to (a) the river $\left(S_{\text {iRiver }}\right)$ and (b) the Irish coast $\left(S_{\text {iCoast }}\right)$ at 3 levels of sea lice density at the Killary salmon farm during the smolt run. Error bars are $95 \%$ confidence intervals

$44.6 \%$, range $=0.6 \%$ to $262.7 \%$ ) for the Early value of $Y_{i}$, suggesting that the lice impact is meaningful in the context of background environmental forcing. This comparison showed similar results for $S_{\text {iCoast }}$.

\section{Predicting the contribution of sea lice impacts to long-term returns of Erriff salmon}

Adult-to-adult Ricker SR curves, assuming a 4 yr generation time, showed a (visually) reasonable fit for both river and coast returns, suggesting that estimates of $R p$ and $S p$ were acceptable (Fig. 6). Comparing observed salmon returns $S_{i}$ with licecorrected returns $S_{\text {tot }}$ for $S_{\text {iRiver }}$ and $S_{\text {iCoast }}$ (Fig. 7) showed that while the sea lice effect can strongly reduce annual returns $S_{i}$, 'correcting' for this effect 

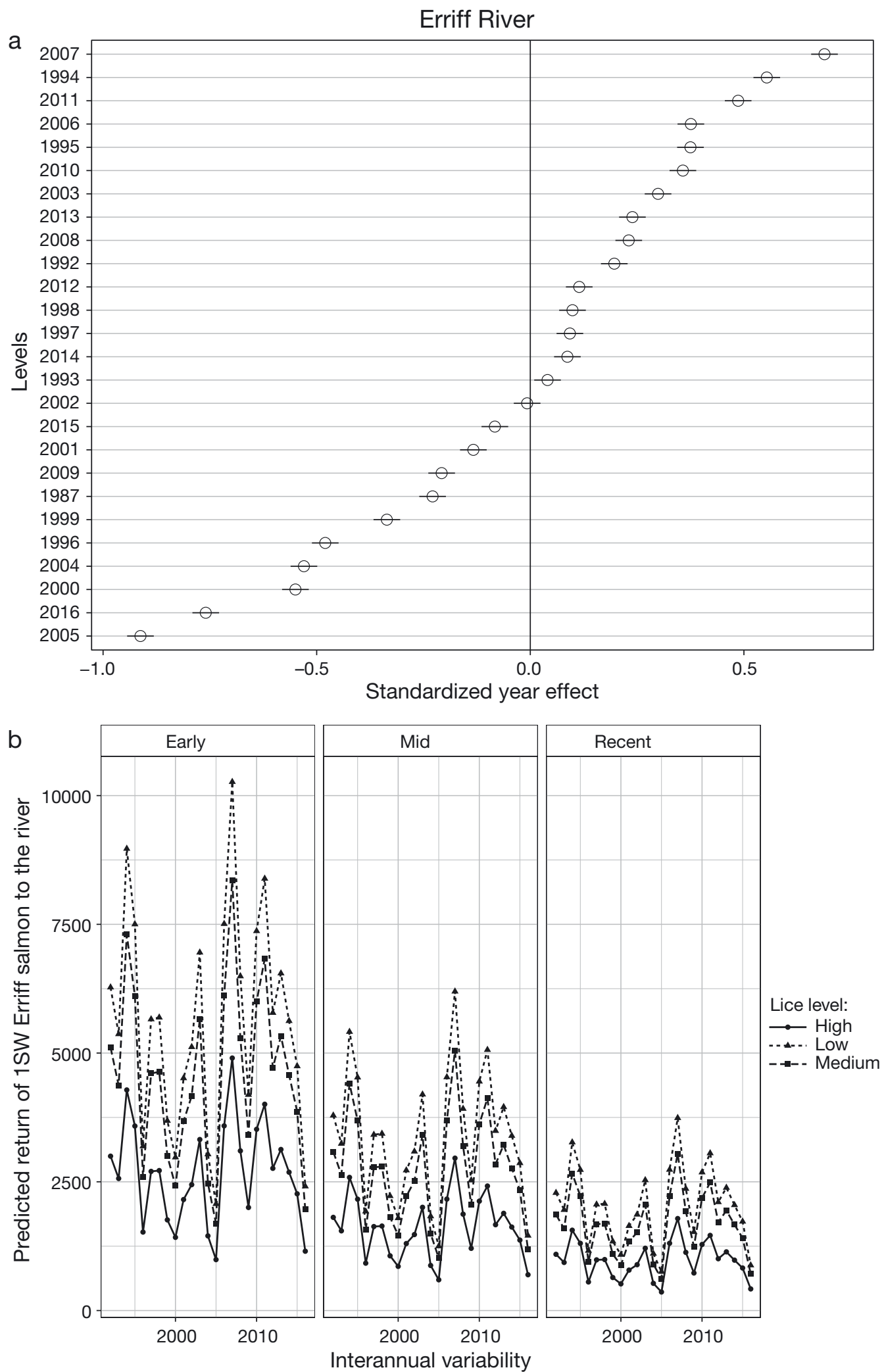

Fig. 5. (a,c) Random effects (with 95\% CI) on the intercept of year ( Ycat $_{i}$ ) from the selected model (Model 7, Table 1) of returns of 1 sea-winter (1SW) Erriff River Atlantic salmon to (a) the river $\left(S_{\text {iRiver }}\right)$ and (c) the Irish coast $\left(S_{\text {iCoast }}\right)$. (b,d) Random year effect (assumed to express unexplained inter-annual variability) on predicted returns of these salmon to (b) the river and (d) the Irish coast in 3 different periods of the return time series (Early, Mid, Recent) and at 3 levels of estimated salmon lice infestation 

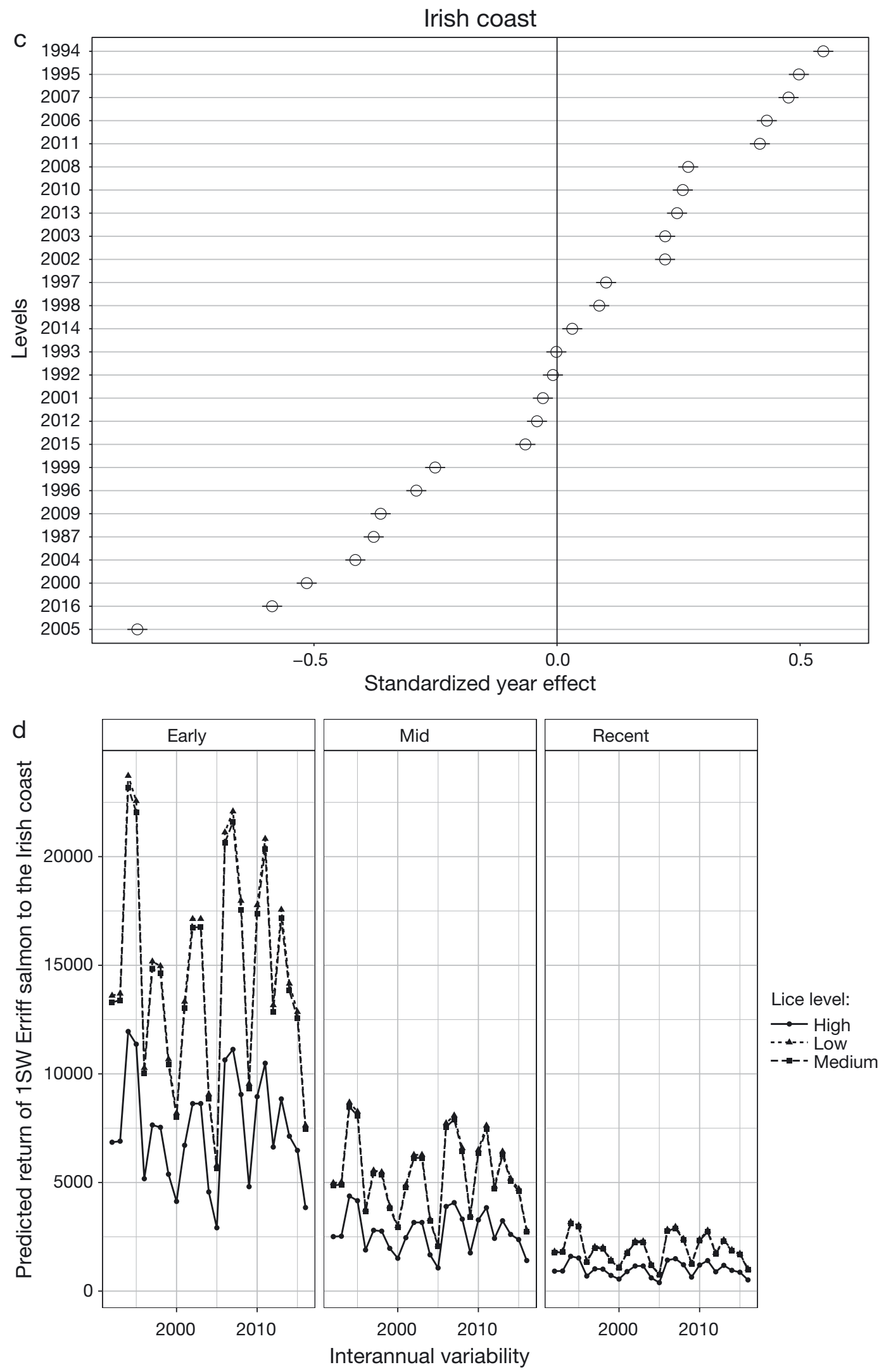

Fig. 5 (continued) 

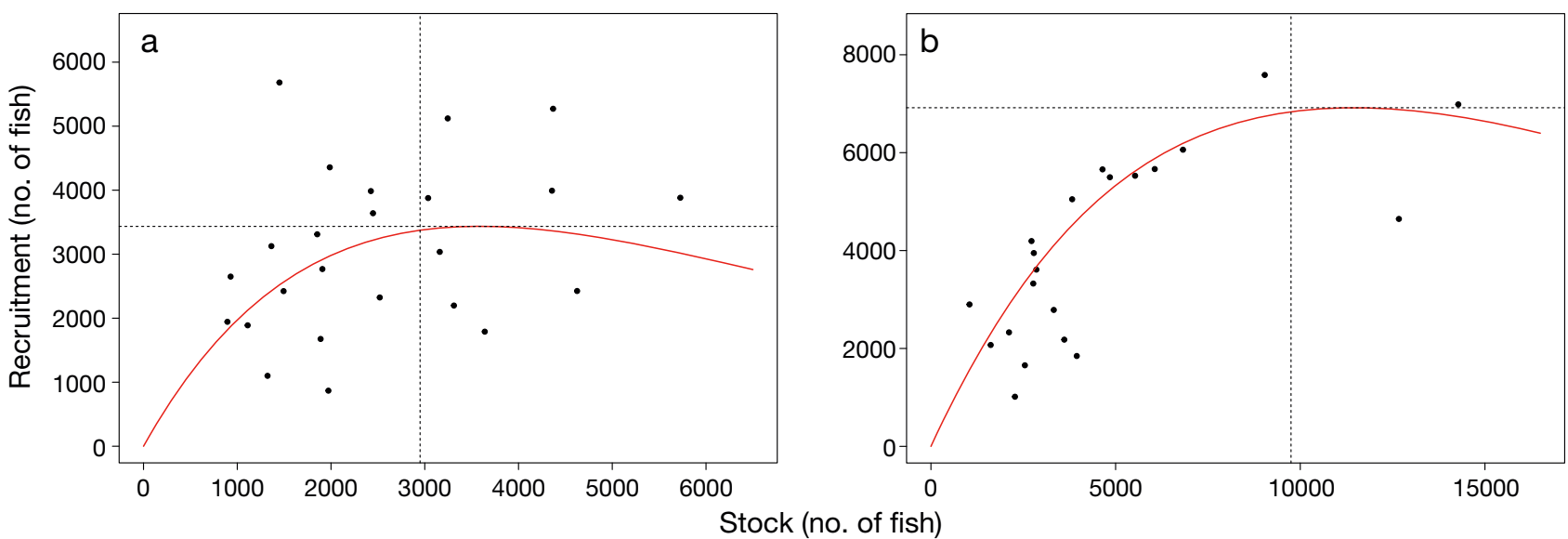

Fig. 6. Ricker stock recruitment curves fit to adult-to-adult stock-recruitment data for 1 sea-winter (1SW) Erriff River Atlantic salmon returns to (a) the river $\left(S_{\text {iRiver }}\right)$ and (b) the Irish coast $\left(S_{\text {iCoast }}\right)$. Stock values are observed returns; recruitment values are 'corrected' according to the annual lice effect estimated from statistical models. A 4 yr generation time (adult return to adult return) is assumed. The horizontal dashed lines are peak recruitment $(R p)$ and the vertical lines are peak stock $(S p)$

does not remove the declining trend. The marked decline in the last $3 \mathrm{yr}$ of both time series reflects relatively low estimated salmon return rates $R R_{i}$ for these years (Table 3).

\section{DISCUSSION}

We analysed a $30 \mathrm{yr}$ time series of returns of 1SW Erriff salmon, with $26 \mathrm{yr}$ of corresponding estimated lice counts from the Killary salmon farm. Wild salmon returns were strongly reduced $(>50 \%)$ following years when there had been high lice levels on the salmon farm during the smolt out-migration. This result accounts for the effect of unexplained amongyear variation in returns, which probably reflects how marine survival varies naturally independent of

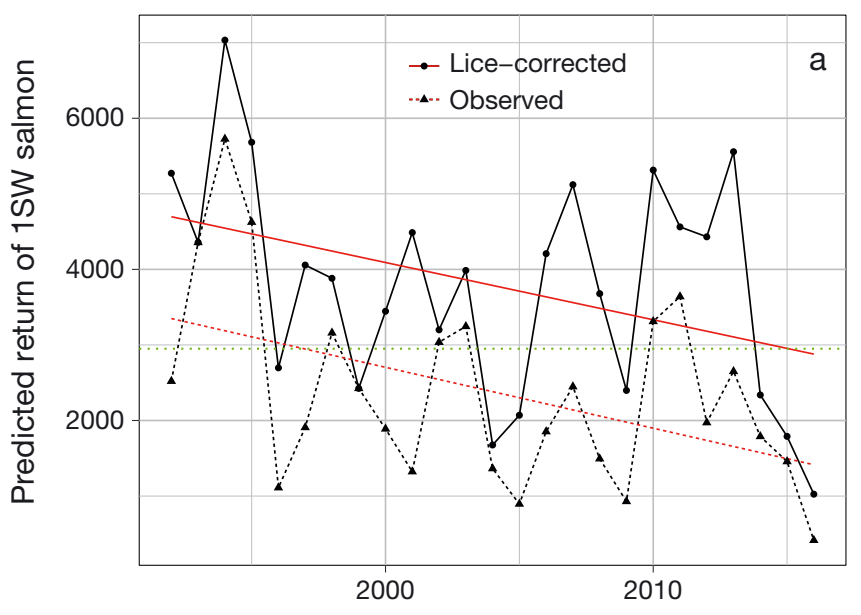

Fig. 7. Observed $\left(S_{i}\right)$ and 'lice-corrected' $\left(S e_{i}\right)$ returns of 1 sea-winter (1SW) Erriff River Atlantic salmon to (a) the river and

(b) the Irish coast. The green line is peak recruitment $(R p)$ estimated from the Ricker curve (see Fig. 6) lice-induced mortality (Vollset et al. 2016). 'Correcting' for the estimated lice effect predicted that Erriff salmon returns might now be twice as large without observed anthropogenic sea lice impacts, but would probably show a similar long-term decline.

Infectious disease is a contributing factor in $8 \%$ of cases where a species is listed by the IUCN as Critically Endangered (Smith et al. 2006). Peacock et al. (2013) estimated that the percentage mortality of pink salmon in the Broughton Archipelago of British Columbia, Canada, due to sea lice infestations ranged from $3.8 \%$ for returns in 2010 to $90.1 \%$ for returns in 2002; Bateman et al. (2016) estimated that liceinduced mortality in the same region was 9 to $39 \%$ in 2015. Our results demonstrate that sea lice infestation from coastal salmon aquaculture is likely to be an important contributor to observed decline in

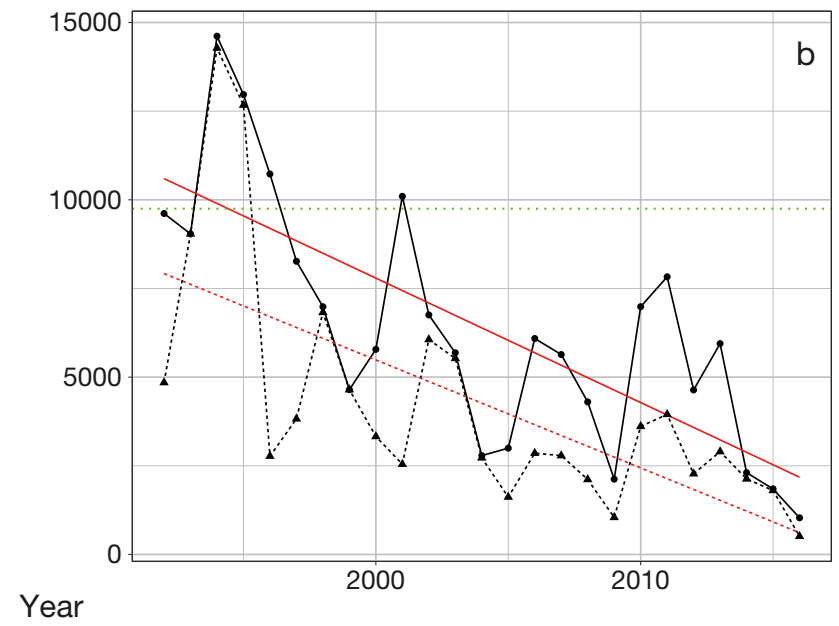


Table 3. Estimated annual adult-to-adult return rates $\left(R R_{i}\right)$ for 1 sea-winter (1SW) Erriff River Atlantic salmon to the river or the Irish coast

\begin{tabular}{|ccc|}
\hline Year & River $R R_{i}$ & Coast $R R_{i}$ \\
\hline 1992 & 1.21 & 0.99 \\
1993 & 2.01 & 1.74 \\
1994 & 3.68 & 3.58 \\
1995 & 3.78 & 4.91 \\
1996 & 1.02 & 1.29 \\
1997 & 1.02 & 0.95 \\
1998 & 0.71 & 0.53 \\
1999 & 0.51 & 0.36 \\
2000 & 1.51 & 1.06 \\
2001 & 1.61 & 1.40 \\
2002 & 1.05 & 0.99 \\
2003 & 1.58 & 1.16 \\
2004 & 0.86 & 0.80 \\
2005 & 0.79 & 0.63 \\
2006 & 1.53 & 1.13 \\
2007 & 1.60 & 0.99 \\
2008 & 2.09 & 1.42 \\
2009 & 2.06 & 1.20 \\
2010 & 2.08 & 1.41 \\
2011 & 1.56 & 1.41 \\
2012 & 1.53 & 1.06 \\
2013 & 2.69 & 2.57 \\
2014 & 0.92 & 0.82 \\
2015 & 0.50 & 0.48 \\
2016 & 0.41 & 0.42 \\
\hline
\end{tabular}

returns of wild Atlantic salmon to the Erriff River system. This finding upholds a substantial literature on the impacts of sea lice on salmonids, and successive experiments using anti-parasite lice treatments. A meta-analysis of differential survival between control and parasiticide-treatment groups of cultured Atlantic salmon showed that returns of treated fish were $39 \%$ greater (Krkošek et al. 2012). Our results for the Erriff predict that the return of 1SW salmon migrating in a high lice year may be reduced by more than $50 \%$ compared to the return from wild smolts that were not exposed to high levels of sea lice from salmon aquaculture during early out-migration.

Sea lice present during the spring smolt outmigration through Killary Harbour could have salmon farm and/or wild salmon sources. Gargan et al. (2012) found that the number of wild salmonids was very low during this period, and that sea lice abundance on local farmed salmon was 3 to 4 orders of magnitude greater than the estimate for wild salmonids. A study on the production of sea lice larvae from farmed and wild salmon and its relation to the infestation of wild sea trout found that farmed salmon contributed $95 \%$ of the total production of L. salmonis nauplii in the mid-west Irish coast region (Tully \& Whelan 1993). These observations suggest that sea lice infestation pressure on wild Erriff smolts originates overwhelmingly from aquaculture.

Lice-induced mortality may have 2 components. Short-term mortality probably occurs when attached lice reach the pre-adult and adult life stages, causing severe osmoregulatory problems indicated by highly elevated plasma chloride levels and increased plasma osmolality (Bjørn \& Finstad 1997, Dawson et al. 1998, Wells et al. 2006). A longer-term reduction in survival may be associated with impacts that impair on-going fitness during migration. The impact of sea lice seems to vary with baseline survival of salmon; a meta-analysis of studies using anti-parasite treatments on salmon smolts found that in groups with low recapture in the control group (low baseline survival), the effect of treatment was high, while in groups with high recapture in the control group (high baseline survival), there was no effect of treatment (Vollset et al. 2016). This result implies that the detrimental effect of lice is exacerbated in situations when the salmon smolts also have to cope with increased pressure from other causes of mortality, e.g. unfavourable environmental conditions. A post hoc plot of standardised salmon returns to the Erriff $S_{\text {iRiver }}$ shows that observed returns approximately track the random year effect $Y_{c} a t_{i}$ (expressing environmental variability). However, the 4 lowest returns on record occurred when a high lice year coincided with poor baseline survival, while the only 2 occasions when a high lice year produced a greater than average run (1992 and 2007) were during high baseline survival (Fig. 8).

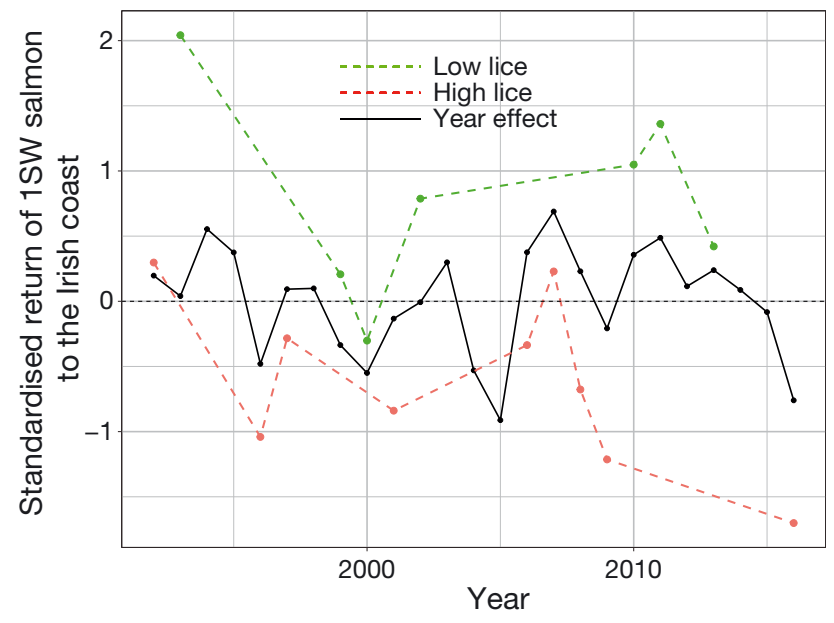

Fig. 8. Observed Erriff River Atlantic salmon returns to the river $\left(S_{\text {iRiver }}\right)$, standardised to 0 for years estimated to have 'High' and 'Low' levels of sea lice (years of Medium lice level are excluded for clarity). Year effect is the random effect of year $\left(Y_{c a t}\right)$, assumed to express environmental effects on salmon returns 
Our results show very low return rates of Erriff salmon in the most recent years, corresponding to apparent declines in marine survival of Atlantic salmon (ICES 2016). Oceanic life stages of salmon are susceptible to climate forcing by the NAO and the AMO that drive SST and thus thermal habitat (Friedland et al. 1993, 2003, Jonsson \& Jonsson 2004, Mills et al. 2013) and associated prey dynamics (Beaugrand \& Reid 2012, Defriez et al. 2016). Recent studies suggest that warming SST has had a negative impact on oceanic growth and survival (McCarthy et al. 2008, Todd et al. 2008, Friedland et al. 2009) of Atlantic salmon, possibly mediated through productivity and trophic interactions (Beaugrand \& Reid 2003, Mills et al. 2013). Hence, aquaculture sea lice impacts on wild Atlantic salmon are imposed upon possibly declining baseline survival.

The negative effect of sea lice from aquaculture may be unusually strong for the Erriff wild salmon population because the Killary salmon farm is located in the mouth of a long and narrow fjord. It is also the case that the $26 \mathrm{yr}$ time series of salmon runs and lice counts, while valuable, still refer to only a single system. A preliminary analysis using these records attempted to identify specific environmental components of marine mortality in addition to sea lice. There were insufficient data for this exercise and so the simpler and more robust random year approach presented here was followed. Despite this limitation, it seems reasonable to expect important lice impacts in other systems where salmon farm(s) with high spring lice levels occur in bays and estuaries with rivers having wild salmon populations. A study of chemically treated and untreated salmon smolt releases in 3 west of Ireland bays (including Killary) found that lice-induced mortality of adult salmon can be significant, and that an increase in mortality of salmon smolts can be expected where farm lice levels are not maintained at sufficiently low levels in spring (Gargan et al. 2012). This observation is consistent with research on pink salmon (e.g. Bateman et al. 2016). A potential $50 \%$ lice-induced reduction in annual return of wild Atlantic salmon is likely to have serious general implications for long-term viability of populations in aquaculture areas. Natal homing in salmon results in a high level of genetic structuring, and smaller salmon rivers typically have a relatively low effective population size (Nikolic et al. 2009). As such populations decline, they are likely to become vulnerable to inbreeding and related demographic problems (e.g. Lande et al. 2003) that can erode future evolutionary potential of salmon populations (McGinnity et al. 2003) and lead to an extinction vortex (Fagan \& Holmes 2006). Many Atlantic salmon populations are already under pressure from (possibly climate-mediated) reductions in marine survival. The addition of significant licerelated mortality during the coastal stage of smolt out-migration could be critical.

Acknowledgements. The Inland Fisheries Ireland staff at the Erriff are gratefully acknowledged for operation of fish counter facilities and provision of rod catch data.

\section{LITERATURE CITED}

Anon (2008) National Atlantic Salmon Genetic Stock Identification Project ST-05-002. Final Report January 2008. Prepared by University College Cork, the Central \& Regional Fisheries Boards and the Irish Marine Institute. Funded under the Irish National Development Plan. www.fisheries ireland.ie/fisheries-research-1/1409-national-salmongenetic-stock-identification-project-report-2008/file

Bateman AW, Peacock SJ, Connors B, Polk Z, Berg D, Krkošek M, Morton A (2016) Recent failure to control sea louse outbreaks on salmon in the Broughton Archipelago, British Columbia. Can J Fish Aquat Sci 73:1164-1172

Bates D, Maechler M, Bolker B, Walker S (2015) lme4: Linear mixed-effects models using Eigen and S4. R package version 1.1-9. https://CRAN.R-project.org/package=lme4

Beaugrand G, Reid PC (2003) Long term changes in phytoplankton, zooplankton and salmon related to climate. Glob Change Biol 9:801-817

* Beaugrand G, Reid PC (2012) Relationships between North Atlantic salmon, plankton, and hydroclimatic change in the Northeast Atlantic. ICES J Mar Sci 69:1549-1562

Bjørn PA, Finstad B (1997) The physiological effects of salmon lice infection on sea trout post smolts. Nord J Freshw Res 73:60-72

Costello MJ (2009) How sea lice from salmon farms may cause wild salmonid declines in Europe and North America and be a threat to fishes elsewhere. Proc R Soc Lond B Biol Sci 276:3385-3394

Wawson LHJ, Pike AW, Houlihan DF, McVicar AH (1998) Effects of salmon lice Lepeophtheirus salmonis on sea trout Salmo trutta at different times after seawater transfer. Dis Aquat Org 33:179-186

* Defriez EJ, Sheppard LW, Reid PC, Reuman DC (2016) Climate change-related regime shifts have altered spatial synchrony of plankton dynamics in the North Sea. Glob Change Biol 22:2069-2080

Elston DA, Moss R, Boulinier T, Arrowsmith C, Lambin X (2001) Analysis of aggregation, a worked example: numbers of ticks on red grouse chicks. Parasitology 122: 563-569

Fagan WF, Holmes EE (2006) Quantifying the extinction vortex. Ecol Lett 9:51-60

Fox F (2003) Effect displays in R for generalised linear models. J Stat Softw 8:1-27

*Frazer L (2009) Sea-cage aquaculture, sea lice, and declines of wild fish. Conserv Biol 23:599-607

Friedland KD, Reddin DG, Kocik JF (1993) Marine survival of North American and European Atlantic salmon: effects of growth and environment. ICES J Mar Sci 50: 481-492 
Friedland KD, Reddin DG, Castonguay M (2003) Ocean thermal conditions in the post-smolt nursery of North American Atlantic salmon. ICES J Mar Sci 60:343-355

Friedland KD, MacLean JC, Hansen LP, Peyronnet AJ and others (2009) The recruitment of Atlantic salmon in Europe. ICES J Mar Sci 66:289-304

Gargan PG, Forde G, Hazon N, Russell DJF, Todd CD (2012) Evidence for sea lice-induced marine mortality of Atlantic salmon (Salmo salar) in western Ireland from experimental releases of ranched smolts treated with emamectin benzoate. Can J Fish Aquat Sci 69:343-353

Harrison XA (2014) Using observation-level random effects to model overdispersion in count data in ecology and evolution. PeerJ 2:e616

Holsman KK, Scheuerell MD, Buhle E, Emmett R (2012) Interacting effects of translocation, artificial propagation, and environmental conditions on the marine survival of Chinook salmon from the Columbia River, Washington, USA. Conserv Biol 26:912-922

Horreo JL, Machado-Schiaffino G, Ayllon F, Griffiths AM, Bright D, Stevens JR, Garcia-Vazquez E (2011) Impact of climate change and human-mediated introgression on southern European Atlantic salmon populations. Glob Change Biol 17:1778-1787

ICES (International Council for the Exploration of the Sea) (2016) ICES advice on fishing opportunities, catch, and effort: North Atlantic Salmon Stocks. Report of the ICES Advisory Committee to the NASCO. ICES Advice 2016, Book 10. ICES, Copenhagen

Johnson LL, Ylitalo GM, Arkoosh MR, Kagley AN and others (2007) Contaminant exposure in outmigrant juvenile salmon from Pacific Northwest estuaries of the United States. Environ Monit Assess 124:167-194

Jonsson B, Jonsson N (2004) Factors affecting marine production of Atlantic salmon (Salmo salar). Can J Fish Aquat Sci 61:2369-2383

Krkošek M, Ford JS, Morton A, Lele S, Myers RA, Lewis MA (2007) Declining wild salmon populations in relation to parasites from farm salmon. Science 318:1772-1775

Krkošek M, Connors BM, Morton A, Lewis MA, Dill LM, Hilborn R (2011) Effects of parasites from salmon farms on productivity of wild salmon. Proc Natl Acad Sci USA 108:14700-14704

Krkošek M, Revie CW, Gargan PG, Skilbrei OT, Finstad B, Todd CD (2012) Impact of parasites on salmon recruitment in the Northeast Atlantic Ocean. Proc R Soc Lond B Biol Sci 280:2012-2359

Lande R, Engen S, Saether BE (2003) Stochastic population dynamics in ecology and conservation. Oxford University Press, Oxford

Larsson P, Backe C, Bremle G, Eklöv A, Okla L (1996) Persistent pollutants in a salmon population (Salmo salar) of the southern Baltic Sea. Can J Fish Aquat Sci 53:62-69

Limburg KE, Waldman JR (2009) Dramatic declines in North Atlantic diadromous fishes. Bioscience 59:955-965

Marty GD, Saksida SM, Quinn TJ (2010) Relationship of farm salmon, sea lice, and wild salmon populations. Proc Natl Acad Sci USA 107:22599-22604

McCarthy JL, Friedland KD, Hansen LP (2008) Monthly indices of the post-smolt growth of Atlantic salmon from

Editorial responsibility: Bengt Finstad,

Trondheim, Norway the Drammen River, Norway. J Fish Biol 72:1572-1588

* McCormick SD, Hansen LP, Quinn TP, Saunders RL (1998) Movement, migration, and smolting of Atlantic salmon (Salmo salar). Can J Fish Aquat Sci 55:77-92

*McGinnity P, Prodöhl P, Ferguson A, Hynes R and others (2003) Fitness reduction and potential extinction of wild populations of Atlantic salmon, Salmo salar, as a result of interactions with escaped farm salmon. Proc R Soc Lond B Biol Sci 270:2443-2450

* Mills KE, Pershing AJ, Sheehan TF, Mountain D (2013) Climate and ecosystem linkages explain widespread declines in North American Atlantic salmon populations. Glob Change Biol 19:3046-3061

Nikolic N, Butler JR, Bagliniere JL, Laughton R, McMyn IA, Chevalet C (2009) An examination of genetic diversity and effective population size in Atlantic salmon populations. Genet Res (Camb) 91:395-412

Ó Maoiléidigh N, White J, Dillane M, Bond N and others (2015) National report for Ireland - the 2014 salmon season. Working Paper 27. ICES Working Group on North Atlantic Salmon, 17th March-26th March 2015, Moncton, Canada. ICES, Copenhagen

*Parrish DL, Behnke RJ, Gephard SR, McCormick SD, Reeves GH (1998) Why aren't there more Atlantic salmon (Salmo salar)? Can J Fish Aquat Sci 55:281-287

* Peacock SJ, Krkošek M, Proboszcz S, Orr C, Lewis MA (2013) Cessation of a salmon decline with control of parasites. Ecol Appl 23:606-620

Shephard S, MacIntyre C, Gargan P (2016) Aquaculture and environmental drivers of salmon lice infestation and body condition in sea trout. Aquacult Environ Interact 8: $597-610$

Smith KF, Sax DF, Lafferty KD (2006) Evidence for the role of infectious disease in species extinction and endangerment. Conserv Biol 20:1349-1357

* Todd CD, Hughes SL, Marshall C, MacLean JC, Lonergan ME, Biuw E (2008) Detrimental effects of recent ocean surface warming on growth condition of Atlantic salmon. Glob Change Biol 14:958-970

* Tully O, Whelan KF (1993) Production of nauplii of Lepeophtheirus salmonis (Krøyer) (Copepoda: Caligidae) from farmed and wild salmon and its relation to the infestation of wild sea trout (Salmo trutta L.) off the west coast of Ireland in 1991. Fish Res 17:187-200

Vollset KW, Krontveit RI, Jansen P, Finstad B and others (2016) Impacts of parasites on marine survival of Atlantic salmon: a meta-analysis. Fish Fish 17:714-730

Wells A, Grierson CE, MacKenzie M, Russon IJ and others (2006) Physiological effects of simultaneous, abrupt seawater entry and sea lice (Lepeophtheirus salmonis) infestation of wild, sea-run brown trout (Salmo trutta) smolts. Can J Fish Aquat Sci 63:2809-2821

White J, Ó Maoiléidigh N, Gargan P, de Eyto E and others (2016) Incorporating natural variability in biological reference points and population dynamics into management of Atlantic salmon (Salmo salar L.) stocks returning to home waters. ICES J Mar Sci 73:1513-1524

Zuur AF, Hilbe JM, Ieno EN (2015) A beginner's guide to GLM and GLMM with R. A frequentist and Bayesian perspective for ecologists. Highland Statistics, Newburgh

Submitted: November 2, 2016; Accepted: March 27, 2017 Proofs received from author(s): April 18, 2017 